Vala, M. A., G. W. Mitchell, K. C. Hannah, J. Put, and S. Wilson. 2020. The effects of landscape composition and configuration on Eastern Whippoor-will (Caprimulgus vociferous) and Common Nighthawk (Chordeiles minor) occupancy in an agroecosystem. Avian Conservation and Ecology 15 (1):24. https://doi.org/10.5751/ACE-01613-150124

Copyright (C) 2020 by the author(s). Published here under license by the Resilience Alliance.

Research Paper

\title{
The effects of landscape composition and configuration on Eastern Whip-poor-will (Caprimulgus vociferous) and Common Nighthawk (Chordeiles minor) occupancy in an agroecosystem
}

\author{
Michelle A. Vala ${ }^{1}$, Greg W. Mitchell ${ }^{1,2}$, Kevin C. Hannah ${ }^{3}$, Julia E. Put ${ }^{1}$ and Scott Wilson ${ }^{1,2,4}$ \\ ${ }^{1}$ Department of Biology, Carleton University, Ottawa, Ontario, Canada, ${ }^{2}$ Wildlife Research Division, National Wildlife Research \\ Centre, Environment and Climate Change Canada, Ottawa, Ontario, Canada, ${ }^{3}$ Canadian Wildlife Service, Environment and \\ Climate Change Canada, Ottawa, Ontario, Canada, ${ }^{4}$ Department of Forest and Conservation Sciences, University of British \\ Columbia, Vancouver, British Columbia, Canada
}

\begin{abstract}
Agricultural expansion and intensification are some of the leading drivers of biodiversity loss globally. Effective conservation and management strategies for threatened species in agroecosystems require information on how these species are affected by (1) the amount and configuration of natural habitats, and (2) the type and extent of agricultural land covers. The Eastern Whippoor-will (Caprimulgus vociferous) and Common Nighthawk (Chordeiles minor) are two nocturnal aerial insectivores in decline in North America, and have breeding ranges that include agriculturally dominated landscapes. We first assessed mean breeding occupancy of both species in eastern Ontario, Canada in 2016 using acoustic recording units at 127 sites. We then assessed the effects of landscape composition (forest, agriculture, wetlands, and urban covers), forest configuration (mean patch size, number of patches, distance to nearest patch), and agriculture type (perennial forages versus cropland) on Eastern Whip-poor-will occupancy. Eastern Whip-poorwill and Common Nighthawk occupancy in the study area averaged 0.244 and 0.064 , respectively. We were unable to examine the relationships between landscape composition/configuration and Common Nighthawk occupancy because of small sample sizes. Nonetheless, Eastern Whip-poor-will occupancy was positively correlated with the amount of wetland cover and forest patch size, was weakly negatively correlated with urban land cover, and was unrelated to the type of agriculture. Our results highlight how the conservation of the Eastern Whip-poor-will in agricultural landscapes of eastern Canada would benefit from both wetland protection and the presence of larger forest patches, which can be accomplished through both forest protection and by allowing forest regeneration on abandoned lands.
\end{abstract}

\section{Les effets de la composition et de la configuration du paysage sur la présence de l'Engoulevent bois- pourri (Caprimulgus vociferous) et de l'Engoulevent d'Amérique (Chordeiles minor) dans un agroécosystème}

RÉSUMÉ. L'expansion et l'intensification de l'agriculture sont parmi les causes principales de perte de biodiversité à l'échelle mondiale. Pour que les stratégies de conservation et de gestion des espèces menacées vivant dans les agroécosystèmes soient efficaces, il est important de savoir comment ces espèces sont affectées par (1) la superficie et la configuration des milieux naturels, et (2) le type et l'étendue des terres agricoles. L'Engoulevent bois-pourri (Caprimulgus vociferous) et l'Engoulevent d'Amérique (Chordeiles minor) sont deux insectivores aériens nocturnes en diminution en Amérique du Nord, et leur aire de nidification comprend des paysages dominés par l'agriculture. Premièrement, nous avons déterminé la présence de ces deux espèces au moment de la nidification dans l'est de l'Ontario, Canada, à l'aide d'enregistreurs automatiques à 127 sites en 2016. Nous avons ensuite évalué les effets de la composition du paysage (couvert forestier, agricole, de milieux humides ou urbain), de la configuration forestière (taille moyenne de l'îlot, nombre d'îlots, distance à l'îlot le plus près) et du type agricole (culture annuelle ou pérenne) sur la présence de l'Engoulevent bois-pourri. L'occurrence de l'Engoulevent bois-pourri et de l'Engoulevent d'Amérique dans l'aire d'étude était de 0,244 et 0,064 en moyenne, respectivement. Nous avons été incapables d'examiner les relations entre la composition/configuration du paysage et l'Engoulevent d'Amérique en raison du faible nombre d'échantillons. Néanmoins, la présence de l'Engoulevent bois-pourri était corrélée positivement avec la superficie de milieux humides et la taille des îlots forestiers, faiblement corrélée négativement avec le milieu urbain, et non corrélée au type d'agriculture. Nos résultats soulignent que la protection des milieux humides et la présence d'îlots forestiers plus grands profiteraient à la conservation de l'Engoulevent bois-pourri en paysage agricole dans l'est du Canada, et que tous deux peuvent être assurées par la protection des forêts et en laissant la forêt se régénérer sur les terres abandonnées.

Key Words: aerial insectivores; agroecosystems; landscape composition; landscape configuration; occupancy; scale of effect; species at risk

Address of Correspondent: Michelle A Vala, michellevala@cmail.carleton.ca, 9660 Hwy 15, Smiths Falls, ON , K7A 4S7, Canada,

michellevala5@gmail.com 


\section{INTRODUCTION}

The expansion and intensification of agriculture is a primary driver of declines in avian populations (Donald et al. 2001, Benton et al. 2003, Evans et al. 2007, Paquette et al. 2013). In eastern Canada, there has been a profound change in agricultural land use from pastoral to more intensive arable crop agriculture (Statistics Canada 2006). This trend is associated with a shift toward greater synthetic agrochemical use, which started in the 1970s (e.g., Boutin and Jobin 1998), and to a higher loss of natural and seminatural land covers, thus raising concern about how these changes have affected the avian community (Wilson et al. 2017, Endenburg et al. 2019). Numerous threatened species co-occur in agroecosystems, and the development of effective conservation and management strategies for these species requires that we understand how they respond to the expansion and intensification of agriculture (Caughley 1994, Guisan et al. 2013). Such information is aided by knowledge of three key components: (1) the tolerance of species to compositional change in preferred habitat (Lindenmayer et al. 2005, Swift and Hannon 2010, SuarezRubio et al. 2013), (2) whether the configuration of preferred habitat affects species, and (3) the spatial scales at which species are most responsive to habitat loss, which allows for the management of habitat at the scale most likely to be influential for species recovery (Jackson and Fahrig 2015, Farrell et al. 2019).

The Eastern Whip-poor-will (Caprimulgus vociferous) and the Common Nighthawk (Chordeiles minor) are two examples of nocturnal aerial insectivores that have experienced long-term population declines along with several other aerial insectivorous bird species (Nebel et al. 2010, Michel et al. 2016, Spiller and Dettmers 2019). In North America between 1970 and 2017, Eastern Whip-poor-will and Common Nighthawk populations declined by $74 \%$ and $56 \%$, respectively (Smith et al. 2019), and under Canada's Species at Risk Act, they are listed as Threatened and Special Concern, respectively (Environment and Climate Change Canada 2019). Several factors have been hypothesized as contributing to observed declines in Eastern Whip-poor-will populations, including reduced food availability and habitat loss on the breeding grounds (Boettner et al. 2000, Hallmann et al. 2014, Tozer et al. 2014, English et al. 2017), and habitat loss on the wintering grounds (Cink et al. 2017). Threats to Common Nighthawks are poorly known, in part because a large proportion of the Canadian population breeds in remote areas of the boreal forest where distribution and trend information is limited (Farrell et al. 2017, 2019).

The Eastern Whip-poor-will and Common Nighthawk are associated with semi-open habitats, which raises the possibility that individuals may use agricultural areas similar to their use of clearcut patches in forested landscapes (Brigham et al. 2011, Tozer et al. 2014, Cink et al. 2017, Farrell et al. 2017, 2019). Eastern Whip-poor-wills are strongly associated with open canopy forest and edge habitat for nesting, roosting, and increased visibility for foraging at night (Tozer et al. 2014, Akresh and King 2016, Cink et al. 2017, English et al. 2017). The importance of various components of landscape structure for Eastern Whip-poor-wills appears to be scale-dependent. For example, in relatively intact forested regions, forest amount has been found to influence Eastern Whip-poor-will presence at a broad landscape scale, but forest edge appears to be more important at finer spatial scales (Akresh and King 2016, English et al. 2017, Farrell et al. 2019).
Common Nighthawks show variable habitat use, and often use open habitats such as agricultural areas (Brigham et al. 2011) and openings in forested landscapes created by wetlands, fires, or human activities (e.g., forestry) (Farrell et al. 2017).

In this study, we first measured occupancy of the two species within an agricultural region of eastern Ontario. We then assessed the effects of landscape composition (forest, agriculture, wetland, and urban land cover) and forest configuration (mean patch size, number of patches, distance to nearest patch) on Eastern Whippoor-wills. While we intended to examine these same relationships between landscape composition/configuration and Common Nighthawk occupancy, we were unable to do so because of small sample sizes (i.e., models for Nighthawks were unreliable as indicated by standard errors and parameter estimates). For the Eastern Whip-poor-will, we first examined the relationship between occupancy and landscape composition at multiple spatial scales. We then examined if forest configuration and agriculture type (proportion of perennial forages and cropland) were better predictors of Eastern Whip-poor-will occupancy than landscape composition alone. Eastern Whip-poor-wills often select partially open landscapes (Tozer et al. 2014, Farrell et al. 2017, 2019); therefore, these combined objectives were intended to ask (1) whether Eastern Whip-poor-will occupancy of agroecosystems in eastern Canada is higher in more open landscapes with small forest patches or in more closed forested landscapes with larger forest patches, and (2) if occupancy is higher in areas where the agricultural habitat is dominated by perennial forages rather than arable crop. We predicted the latter because of higher food availability and greater habitat suitability in pasture compared to arable crop (Boutin and Jobin 1998, Evans et al. 2007).

\section{METHODS}

\section{Survey design}

Our surveys were conducted during the breeding season (6 June to 19 July 2016) to coincide with the peak in vocal activity of Eastern Whip-poor-wills and Common Nighthawks in eastern Ontario, Canada. We used a spatial road layer in ArcGIS (Esri Inc. 2016) to randomly allocate a sample of survey locations (latitude range: $44^{\circ} 92^{\prime}$ to $45^{\circ} 51^{\prime} \mathrm{N}$; longitude range: $74^{\circ} 41^{\prime}$ to $76^{\circ}$ $73^{\prime} \mathrm{W}$ ) on any accessible road except for primary highways. We placed a constraint on the location of each potential site such that they were at least $4 \mathrm{~km}$ apart. We obtained 205 potential sites of which we identified 127 that represented a gradient along two land cover axes at a 1-km radius: (1) high proportion agriculture (range 0.00-0.96) to high proportion forest (range 0.02-0.93), and (2) within the agricultural land cover class, a high proportion of arable crop types (range $0.00-0.99$ ) to a high proportion of perennial forages (range $0.00-1.00$ ).

\section{Sampling methods}

We used SM2+ autonomous recording units (ARUs [Wildlife Acoustics Inc.]) to sample for Eastern Whip-poor-wills and Common Nighthawks at the 127 selected sites. The ARUs were placed at approximately chest height on a fence post or a tree along the roadside with the microphones extending perpendicular to the road. The ARUs were programmed to make three recordings per day (sunset, $1 \mathrm{~h}$ after sunset, and $1 \mathrm{~h}$ before sunrise) over seven days at each site. Using multiple recordings per site 
Table 1. Summary statistics for landscape covariates. Scale $=$ the scale of effect in meters (see Appendix 1).

\begin{tabular}{|c|c|c|c|c|c|c|}
\hline Covariate & Scale & Description & Mean & Min & $\operatorname{Max}$ & $\mathrm{SD}$ \\
\hline Agriculture & 3000 & Proportion of agriculture in the landscape & 0.43 & 0 & 0.88 & 0.24 \\
\hline Forest & 2000 & Proportion of forest in the landscape & 0.43 & 0.04 & 0.92 & 0.22 \\
\hline Wetland & 6000 & Proportion of wetland in the landscape & 0.060 & 0.003 & 0.240 & 0.050 \\
\hline Urban & 2000 & Proportion of urban in the landscape & 0.050 & 0.007 & 0.250 & 0.040 \\
\hline Cropland & 1000 & Proportion of agriculture in cropland & 0.50 & 0.00 & 0.99 & 0.34 \\
\hline Perennial Forages & 7000 & Proportion of agriculture in perennial forages & 0.41 & 0.15 & 0.88 & 0.21 \\
\hline Mean patch size & 2000 & Forest mean patch size (ha) & 3.99 & 0.42 & 24.70 & 4.45 \\
\hline Number of patches & 2000 & Total number of forest patches & 149 & 44 & 289 & 55 \\
\hline Forest distance & 2000 & Distance to nearest forest patch $>1800 \mathrm{~m}^{2}$ & 83.96 & 0 & 553.47 & 114.74 \\
\hline
\end{tabular}

allowed us to estimate occupancy of the two species while accounting for temporal variation and the effects of background noise on detectability (MacKenzie et al. 2002). After the field season, a single observer selected four days per site with the lightest wind conditions and little-to-no rain, and listened to the first $5 \mathrm{~min}$ of each 10-min recording for each of the three daily time periods. Thus, with this sampling schedule, we had a total of 12 replicate surveys per site (i.e., three recordings per day over four days). Detections of all Eastern Whip-poor-wills or Common Nighthawks heard on the recordings were noted. The observer recorded multiple individuals of a species when it was possible to determine that two or more were calling; however, for consistency, only occurrence information (e.g., detected $=1$, or not detected $=$ 0 ) was subsequently used in the analysis. During each recording, the listener noted any significant disturbances (e.g., vehicle, equipment malfunction) that might influence detectability of calling individuals. Noise, wind, and rain were all classified as binomial variables (included as $1 / 0$ categorical variables), while vehicular disturbances were quantified as a count of the number of passing vehicles. We included recordings with low wind or light drizzle.

\section{Landscape variables}

We obtained the landscape cover types from the 2016 Agriculture and Agri-Food Canada (AAFC) annual crop inventory (Fisette et al. 2013), which includes major land cover types in Canada mapped at a $30-\mathrm{m}$ spatial resolution. The AAFC inventory includes 66 land cover classes representing natural, agricultural, and urban land covers. We grouped together various land cover types to create forest and agricultural land covers. The forest land cover consisted of three classes: mixedwood, broadleaf, and coniferous forest. Agricultural land cover consisted of 35 land cover classes, including all grains, vegetables, fruits, grasses, crop fields, vineyards, and greenhouses. Cropland consisted of a subset of these: 20 classes of annual row crops, which were predominantly corn, soy, and wheat, but also included vegetables and fruits. Perennial forages included periodically cultivated land with tame grasses and other perennial crops such as alfalfa and clover grown alone or as mixtures for hay, pasture, or seed (Statistics Canada 2011). We also used the wetland and urban land covers from the AAFC inventory to quantify the amount of wetland and urban cover in the landscape.

To assess scale of effect (sensu Jackson and Fahrig 2015; see scale of effect analysis in Appendix 1), we measured the amount of each land cover type at 11 spatial scales from the survey point using circular buffers with the following radii: $500 \mathrm{~m}, 1000 \mathrm{~m}, 2000 \mathrm{~m}$,
$3000 \mathrm{~m}, 4000 \mathrm{~m}, 5000 \mathrm{~m}, 6000 \mathrm{~m}, 7000 \mathrm{~m}, 8000 \mathrm{~m}, 9000 \mathrm{~m}$, and $10000 \mathrm{~m}$. For landscape composition measures (i.e., amount of forest, agriculture, wetland, urban land cover), we divided the amount of land cover by the total landscape area to calculate the proportion of each land cover type. To assess how the proportion of different agriculture types (perennial forages versus row crops) affects occupancy, we divided the amount of perennial forages and cropland by the total amount of agriculture in the landscape (Put et al. 2019).

To assess landscape configuration with respect to forest cover, we measured forest patch configuration metrics using Patch Analyst 5 (Rempel et al. 2012), an ESRI ArcMap extension (Esri Inc. 2016). The configuration metrics included mean patch size (in hectares), total number of patches, and distance to nearest forest patch (distance in meters to patches larger than $1800 \mathrm{~m}^{2}$ ). All forest patch configuration metrics were calculated at 2000-m radius buffers around each site, which corresponded to the most significant scale of effect for Eastern Whip-poor-will response to forest composition (see scale of effect analysis in Appendix 1). We calculated and summarized statistics for the mean, minimum, maximum, and standard deviation of each landscape variable (Table 1).

\section{Statistical analysis}

We conducted analyses in R Version 3.5.2 (R Core Team 2017) and used single-season occupancy models from the package "unmarked" (Fiske and Chandler 2020). We examined occupancy and detectability for both species, and then developed more complex models to test the effects of potentially influential predictor variables, including landscape variables, on Eastern Whip-poor-will occupancy while accounting for detection probability (MacKenzie et al. 2002). We evaluated the bivariate correlation (Pearson correlation coefficient [PCC]) between predictor variables to ensure that variables included in the same model were not highly correlated. Pairs of predictor variables were considered correlated if the PCC value was greater than 0.7 or less than -0.7. Correlated predictor variables were not included in the same models but were evaluated separately to determine which variable had the most explanatory power.

Small-sample Akaike's information criterion (AIC $)$ was used to evaluate the support of models containing different variables (Table 2). We first tested for effects on detectability with a comparison among models that included the time of the recording as a categorical variable (i.e., $1 \mathrm{~h}$ after sunset and $1 \mathrm{~h}$ before sunrise), date, number of passing cars, and presence of wind, rain, 
Table 2. Model selection results of the complete candidate set of models for estimating occupancy probability of the Eastern Whip-poor-will. $+=$ addition of covariate to the model, $\mathrm{k}=$ number of parameters in the model, $\triangle \mathrm{AICc}=$ difference in small-sample Akaike's Information Criteria from the model with smallest Akaike's Information Criteria, wi = Akaike weight.

\begin{tabular}{|c|c|c|c|c|}
\hline Detection & Occupancy & $\Delta \mathrm{AIC}_{\mathrm{c}}$ & $\mathrm{k}$ & $\mathrm{w}_{\mathrm{i}}$ \\
\hline time + wind & mean patch size + wetland $(6000 \mathrm{~m})$ & 0.0 & 7 & 0.23 \\
\hline time + wind & mean patch size + wetland $(6000 \mathrm{~m})+\operatorname{urban}(2000 \mathrm{~m})$ & 0.9 & 8 & 0.15 \\
\hline time + wind & mean patch size + urban $(2000 \mathrm{~m})$ & 1.1 & 7 & 0.14 \\
\hline time + wind & mean patch size & 1.2 & 6 & 0.13 \\
\hline time + wind & mean patch size + cropland $(1000 \mathrm{~m})$ & 2.0 & 7 & 0.09 \\
\hline time + wind & mean patch size + pasture $(7000 \mathrm{~m})$ & 2.4 & 7 & 0.07 \\
\hline time + wind & forest $(2000 \mathrm{~m})$ & 3.5 & 6 & 0.04 \\
\hline time + wind & forest $(2000 \mathrm{~m})+$ pasture $(7000 \mathrm{~m})$ & 3.9 & 7 & 0.03 \\
\hline time + wind & $\operatorname{urban}(2000 \mathrm{~m})+$ forest $(2000 \mathrm{~m})$ & 4.1 & 7 & 0.03 \\
\hline time + wind & forest $(2000 \mathrm{~m})+$ cropland $(1000 \mathrm{~m})$ & 4.1 & 7 & 0.03 \\
\hline time + wind & forest $(2000 \mathrm{~m})+$ forest $(2000 \mathrm{~m})^{2 \dagger}$ & 5.2 & 7 & 0.02 \\
\hline time + wind & wetland $(6000 \mathrm{~m})+$ forest $(2000 \mathrm{~m})$ & 5.4 & 7 & 0.02 \\
\hline time + wind & wetland $(6000 \mathrm{~m})+\operatorname{urban}(2000 \mathrm{~m})+$ forest $(2000 \mathrm{~m})$ & 5.9 & 8 & 0.01 \\
\hline time + wind & forest $(2000 \mathrm{~m})+$ pasture $(7000 \mathrm{~m})+$ pasture $(7000 \mathrm{~m})^{2 \dagger}$ & 5.9 & 8 & 0.01 \\
\hline time + wind & agriculture $(3000 \mathrm{~m})$ & 7.4 & 6 & 0.01 \\
\hline time + wind & number of patches & 16.2 & 6 & 0.00 \\
\hline time + wind & urban $(2000 \mathrm{~m})$ & 17.3 & 6 & 0.00 \\
\hline time + wind & wetland $(6000 \mathrm{~m})$ & 20.3 & 6 & 0.00 \\
\hline time + wind & forest distance & 21.8 & 6 & 0.00 \\
\hline time + wind & intercept & 21.4 & 5 & 0.00 \\
\hline time & intercept & 23.1 & 4 & 0.00 \\
\hline intercept & intercept & 23.5 & 2 & 0.00 \\
\hline time + date & intercept & 24.3 & 5 & 0.00 \\
\hline
\end{tabular}

${ }^{\dagger}$ Represents a non-linear model.

or other noise during the survey; an intercept-only model was used on the occupancy component for these comparisons. Based on the detectability model that had the most support, we proceeded to examine support for models with variables hypothesized to influence occupancy. Our first step in this process was to conduct the scale of effect analysis on each of our land cover composition variables of interest (proportion of forest, agriculture, wetland, urban, cropland, and perennial forages) in order to identify the spatial scale at which composition most strongly influenced occupancy (Appendix 1). Each scale of effect was then used to compare models that included land cover proportions (forest, agriculture, wetland, urban) along with the type of agriculture (i.e., proportion of arable crops versus proportion of perennial forages) and the forest cover configuration metrics.

We examined model fit for our analyses using a parametric bootstrap on the most parameterized model with the highest support in the candidate set (Model 2: mean patch size, wetland, and urban) (Table 2) (Fiske and Chandler 2020). We simulated 200 data sets from the model, and for each, we refit the model to the data and computed a Chi-square fit statistic. We then calculated the Chi-square statistic from our observed data. For a well-fit model, the observed value should not be extreme relative to the values from the bootstrapped distribution, and we used $p$ $>0.05$ to indicate adequate fit (Fiske and Chandler 2020). The goodness-of-fit indicated that the observed values did not differ significantly from the simulated bootstrapped distribution for the Eastern Whip-poor-will ( $p=0.42)$, which indicated that the models adequately fit the data.

\section{RESULTS}

We detected Eastern Whip-poor-wills at 29 of the 127 sites and Common Nighthawks at 8 the 127 sites (Fig. 1). The mean probability of detection at occupied sites for Eastern Whip-poorwills and Common Nighthawks respectively was $0.255(95 \%$ confidence interval $[\mathrm{CI}]: 0.208,0.302)$ and 0.273 (95\% CI: 0.179 , 0.367) (Fig. 2). The mean probability of occupancy across the study area was $0.244(95 \%$ CI: $0.168,0.320)$ for Eastern Whippoor-wills and 0.064 (95\% CI: 0.021, 0.107) for Common Nighthawks (Fig. 2).

\section{Eastern Whip-poor-will detectability}

Time of day had the largest influence on detectability of Eastern Whip-poor-wills. Detectability was highest $1 \mathrm{~h}$ before sunrise, with a detection probability of 0.433 ( $95 \%$ CI: $0.34,0.52)$, followed by $1 \mathrm{~h}$ after sunset, with a probability of 0.332 (95\% CI: $0.25,0.42)$. We did not detect any Eastern Whip-poor-wills at sunset, and therefore removed the sunset period from the analysis. There was weak support for a negative effect of wind but no effects of date, rain, noise, or number of passing cars (Table 2). Based on these findings, we retained time of day and wind in subsequent models that examined the influence of landscape composition and configuration on Eastern Whip-poor-wills.

\section{Eastern Whip-poor-will occupancy}

The correlation between variables in the top occupancy models (Table 2) ranged between -0.7 and 0.7 . The proportion of forest and mean forest patch size were strongly and positively correlated $(\mathrm{PCC}=0.7)$ and were not included together in any subsequent models. The proportion of wetland was not correlated with mean 
Fig. 1. Study region showing land cover types, survey locations, and sites where Eastern Whip-poor-will (EWPW) and Common Nighthawk $(\mathrm{CNH})$ were observed or not observed.

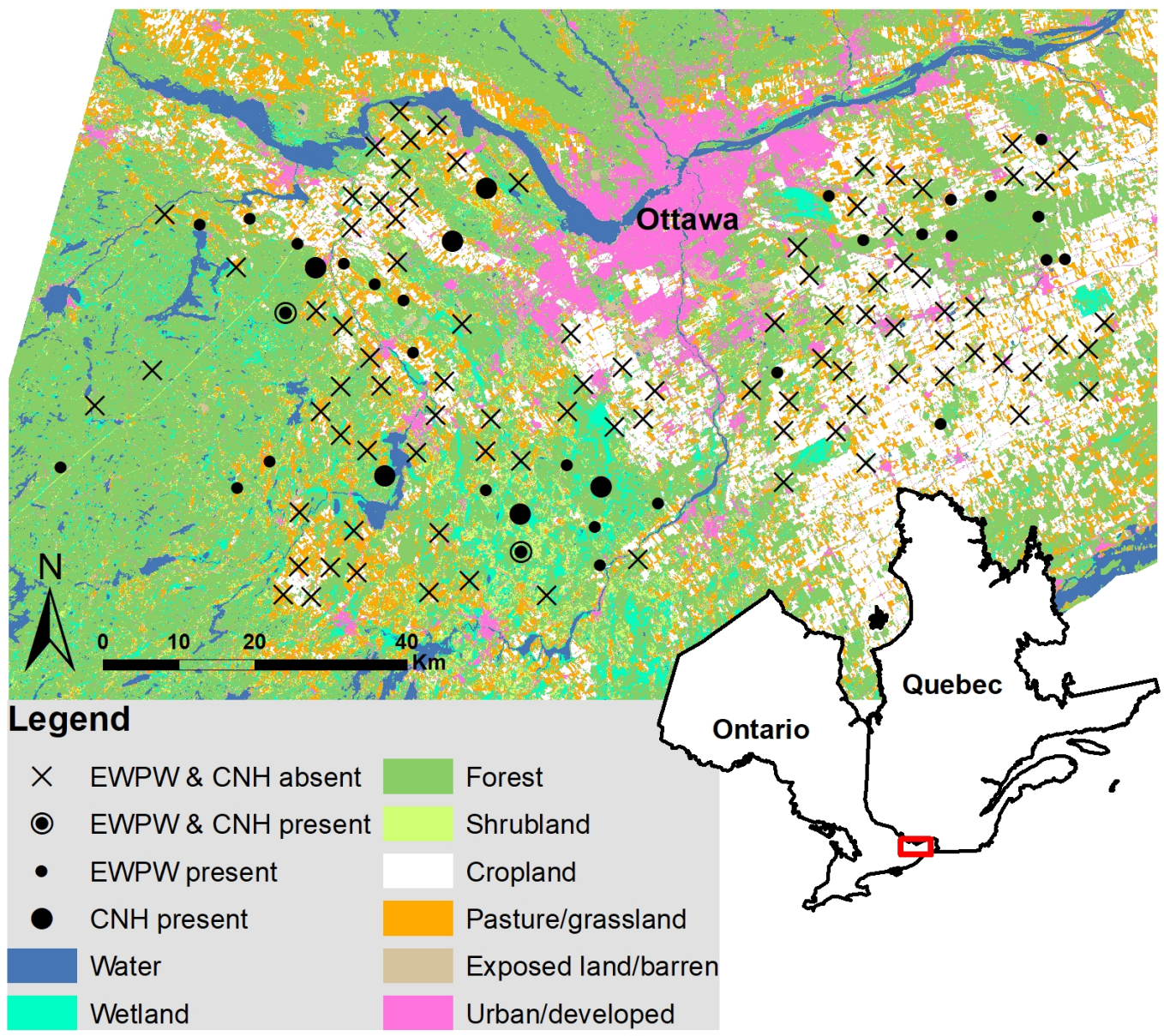

Fig. 2. Mean probability estimate of Eastern Whip-poor-will and Common Nighthawk detection and site occupancy across the study area. Error bars represent standard errors.

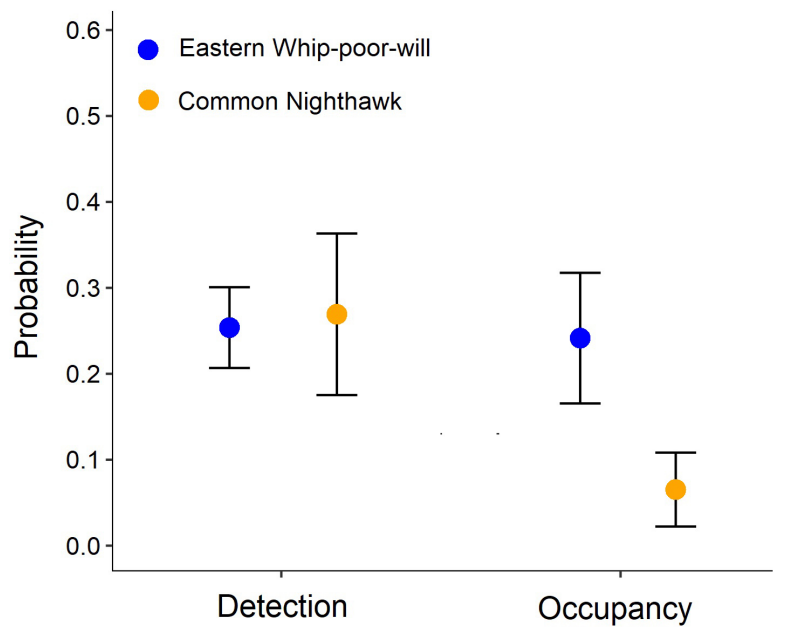

forest patch size $(\mathrm{PCC}=0.05)$ but was moderately positively correlated with proportion of forest $(\mathrm{PCC}=0.47)$. The proportion of urban area showed a slight negative correlation with proportion of forest $(\mathrm{PCC}=-0.25)$, mean forest patch size $(\mathrm{PCC}$ $=-0.2$ ), and proportion of wetlands $(\mathrm{PCC}=-0.21)$. Finally, mean forest patch size and the number of patches were negatively correlated $(\mathrm{PCC}=-0.75)$.

For Eastern Whip-poor-wills, variables in the most supported occupancy model included mean forest patch size and wetland amount (Table 2). Occupancy varied positively with mean patch size $\left(\beta_{\text {patch size }}=0.27 \pm 0.07\right.$ [SE]), which was the most supported configuration variable. More specifically, the relationship between mean patch size and estimated occupancy predicted occupancy estimates of between 0.8 and 1.0 for patches of approximately 15-25 ha (Fig. 3a). Occupancy also varied positively with forest cover at $2000 \mathrm{~m}\left(\beta_{\text {forest }}=4.72 \pm 1.19\right)$ and negatively with the number of forest patches $\left(\beta_{\text {patch number }}=-0.012\right.$ $\pm 0.004)$. Compared to the intercept-only occupancy model, the addition of the two variables individually led to a reduction in AICc of 17.8 and 5.2, respectively. However, mean patch size was the strongest predictor, and because of the correlation among the 
three variables, we did not include all three in the top model. Nevertheless, our results taken together show that Eastern Whippoor-will occupancy tends to be higher in landscapes with greater forest cover in the form of larger patches rather than more open landscapes with a greater number of small forest patches. Eastern Whip-poor-will occupancy also increased with increasing amount of wetland at the $6000-\mathrm{m}$ scale $\left(\beta_{\text {wetland }}=7.38 \pm 4.14\right)$, with the estimate ranging from approximately 0.2 in landscapes without wetlands to 0.4 in landscapes where wetlands represented $25 \%$ of the land cover (Fig. 3b). Occupancy was negatively correlated with urban land cover at the 2000-m scale when considered only with mean patch size $\left(\beta_{\text {urban }}=-11.24 \pm 8.86\right.$; Model 3 in Table 2$)$ but was not supported after accounting for the influence of wetlands $\left(\beta_{\text {urban }}=-8.18 \pm 8.66\right.$; Model 2 in Table 2$)$. While controlling the total proportion of forest in the landscape, we found no evidence that Eastern Whip-poor-will occupancy was related to the type of agriculture, opposite to our prediction (Table 2).

Fig. 3. Estimated Eastern Whip-poor-will occupancy in relation to (a) mean forest patch size and (b) proportion of wetland within $6000 \mathrm{~m}$. Dashed lines show $95 \%$ confidence intervals. Observed presence or absence at each site represented by open circles $(1=$ present, $0=$ absent $)$.
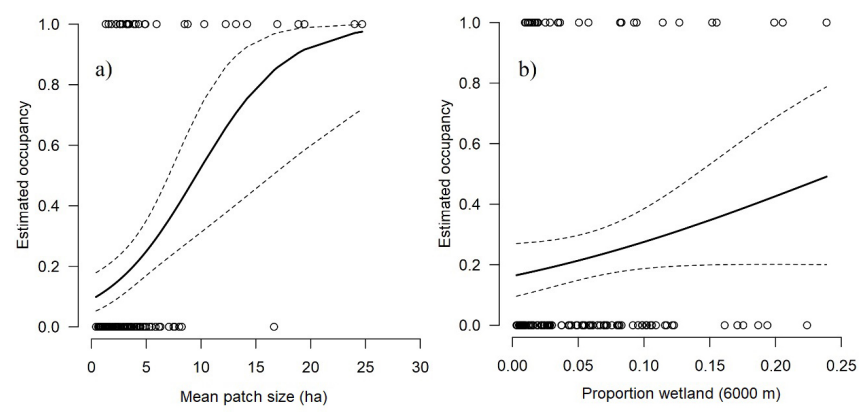

\section{DISCUSSION}

Our study provides novel estimates of mean occupancy for two declining aerial insectivore bird species in an agroecosystem in eastern Canada, and presents important results on the influence of landscape composition and configuration on the occupancy of the Eastern Whip-poor-will. Mean site occupancy for both species in this region was lower than results from studies conducted elsewhere in boreal or eastern hardwood regions, possibly due to the overall openness of the region due to past agricultural and urban expansion. For the Eastern Whip-poorwill, we also found that landscapes with larger forest patches had higher occupancy relative to more open landscapes with small forest patches and that occupancy was greater in areas with higher wetland amount at large spatial scales.

\section{Eastern Whip-poor-will}

Eastern Whip-poor-wills regularly select semi-open habitats on the edge of burns, wetlands, and clearcuts in forested landscapes that provide adjacent foraging and nesting habitat (Wilson 2003, Wilson and Watts 2008, Tozer et al. 2014, Farrell et al. 2017). We tested whether a similar pattern would occur in semi-open agricultural areas in eastern Ontario. However, our results suggest that Eastern Whip-poor-wills preferentially occupy larger forest patches in this region. Edge habitat and small natural or anthropogenic openings may still be beneficial at finer spatial scales, but if so, those effects did not translate to the broad spatial scales we examined (English et al. 2017, Farrell et al. 2019). It is possible that open agricultural land cover does not represent beneficial foraging habitat because of a reduction in insect prey if agrochemicals are applied to agricultural fields (Stoate et al. 2009, Stanton et al. 2018). Alternatively, small forest patches in areas with higher amounts of agriculture may be riskier habitats if potential nest or adult predators such as corvids, foxes, or coyotes are attracted to such landscapes (Bollinger et al. 1990, Gehring and Swihart 2003, Schmidt 2003, Perlut et al. 2006, Stanton et al. 2018). Thus, from a landscape perspective, maintaining larger forest patches appears to be most important in agroecosystems where considerable forest area has already been lost to agriculture.

We found that Eastern Whip-poor-will occupancy was positively related to wetland amount. Wetlands have been shown to be important habitat for this species in the boreal forest of northern Ontario, and they were stronger predictors of landscape-level occupancy than clearcuts, which are also selected at local scales (Farrell et al. 2017, 2019). This relationship with wetlands may be because they provide open areas for foraging and high insect abundance (Spitzer and Danks 2006, COSEWIC 2009). A close relative of the Eastern Whip-poor-will, the European Nightjar, has also been shown to forage more frequently in wetlands than in other open habitat types (Alexander and Cresswell 1990). However, Eastern Whip-poor-will association with wetland habitat is not often reported or emphasized in the literature (e.g., COSEWIC 2009, Tozer et al. 2014, Slover and Katzner 2016, Cink et al. 2017). In eastern Ontario, approximately $72 \%$ of presettlement wetlands have been reduced, and wetlands continue to be threatened (Ducks Unlimited Canada 2010). Our study highlights the importance of considering wetlands in Eastern Whip-poor-will recovery plans.

Our estimate of Eastern Whip-poor-will site occupancy was 0.24, which is lower than other empirical estimates in the literature. For example, occupancy estimates were 0.76 in clearcut areas in sites in central Ontario (Tozer et al. 2014) and 0.75 along the Eastern Gulf Coastal Plains of Mississippi, based on the Breeding Bird Survey (Twedt 2015). In northern Ontario, occupancy estimates were $0.47,0.40$, and 0.36 in burned stands, open wetlands, and clearcuts, respectively (Farrell et al. 2017), and 0.36 in clearcuts in landscapes devoid of burns (Farrell et al. 2019). Our lower occupancy estimates by comparison are likely because our study region contains smaller patches of forest and lower amounts of wetland (relative to these other study areas), and the open habitat is dominated by agricultural land cover, which Eastern Whippoor-wills have been found to avoid elsewhere (Slover and Katzner 2016). Our surveys were conducted along roads, which may have resulted in lower occupancy than at off-road sites if the species shows any road bias (Harris and Haskell 2007). Future research on Eastern Whip-poor-wills in agroecosystems could include onroad and off-road surveys to test this possibility. It is also possible that because we surveyed in only one year, low occupancy estimates may have been further exacerbated by year effects. For 
example, habitat degradation or poor climatic conditions during the nonbreeding season may have resulted in lower than average population sizes on the breeding grounds during our study year (e.g., Wilson et al. 2011, Rushing et al. 2016).

\section{Common Nighthawk}

The low Common Nighthawk occupancy (0.064) we observed in agricultural areas was surprising because other studies have shown that Common Nighthawks use a wide variety of habitats for nesting (Brigham et al. 2011, COSEWIC 2018) and foraging, including agricultural areas, wetlands, water, and urban centers, if food is available (Brigham 1989, Knight et al. 2018). The mean occupancy for Common Nighthawks was only about one-third that of Eastern Whip-poor-wills, while detection estimates were similar (Fig. 2), which suggests that low Common Nighthawk occupancy was not a result of a detectability bias. Results from a study in the boreal forest of northern Ontario showed higher occupancy estimates of 0.44 (Farrell et al. 2017) and 0.67 (Farrell et al. 2019) where forest cover is greater at a regional scale. Additionally, a study in the native Great Plains grasslands in the United States reported an estimated Common Nighthawk occupancy of 0.43 (Stenger et al. 2011). Common Nighthawks were detected primarily in the western region of our study area, which is more forested and has a different geology, including more exposed bedrock, limited drainage, and subsequently more wetlands than other areas in the study region. Because wetlands may provide important foraging habitat, their loss and currently low abundance across much of our study area may have negatively affected Common Nighthawk occupancy (Spitzer and Danks 2006, COSEWIC 2018, Farrell et al. 2019).

\section{CONCLUSION AND CONSERVATION APPLICATIONS}

Our study region represents a landscape fragmented by urban and agricultural activities, similar to many other landscapes within the hardwood forest ecosystems of eastern North America. Management strategies in these types of fragmented agricultural landscapes should emphasize wetland protection and the maintenance of large forest patches; the latter can be encouraged by protecting existing patches and promoting forest regeneration on abandoned lands. This strategy would provide foraging opportunities during early stages of regeneration as well as habitat for roosting and nesting as stands age and reach maturity.

Responses to this article can be read online at: http://www.ace-eco.org/issues/responses.php/1613

\section{Acknowledgments:}

Thanks to Christine Eberl at the National Wildlife Research Center for her assistance and to Lenore Fahrig for providing constructive criticism on early versions of the manuscript. Also, thanks to the Geomatics and Landscape Ecology Lab (GLEL) discussion group for providing helpful comments. Funding for this project was provided by Environment and Climate Change Canada.

\section{LITERATURE CITED}

Akresh, M. E., and D. I. King. 2016. Eastern Whip-poor-will breeding ecology in relation to habitat management in a pitch pine-scrub oak barren. Wildlife Society Bulletin 40(1):97-105. https://doi.org/10.1002/wsb.621

Alexander, I., and B. Cresswell. 1990. Foraging by nightjars Caprimulgus europaeus away from their nesting areas. Ibis 132 (4):568-574. https://doi.org/10.1111/j.1474-919X.1990.tb00280. $\mathrm{X}$

Benton, T. G., J. A. Vickery, and J. D. Wilson. 2003. Farmland biodiversity: Is habitat heterogeneity the key? Trends Ecology \& Evolution 18(4):182-188. https://doi.org/10.1016/S0169-5347(03) 00011-9

Boettner, G. H., J. S. Elkinton, and C. J. Boettner. 2000. Effects of a biological control introduction on three nontarget native species of Saturniid moths. Conservation Biology 14 (6):1798-1806. https://doi.org/10.1111/j.1523-1739.2000.99193.x

Bollinger, E. K., P. B. Bollinger, and T. A. Gavin. 1990. Effects of hay-cropping of eastern populations of the Bobolink. Wildlife Society Bulletin 18(2):143-150.

Boutin, C., and B. Jobin. 1998. Intensity of agricultural practices and effects on adjacent habitats. Ecological Applications 8 (2):544-557. https://doi.org/10.1890/1051-0761(1998)008[0544: IOAPAE]2.0.CO;2

Brennan, J. M., D. J. Bender, T. A. Contreras, and L. Fahrig. 2002. Focal patch landscape studies for wildlife management: optimizing sampling effort across scales. Pages 68-91 in J. Liu and W. W. Taylor, editors. Integrating landscape ecology into natural resource management. Cambridge University Press, Cambridge, UK. https://doi.org/10.1017/CBO9780511613654.006

Brigham, R. M. 1989. Roost and nest sites of Common Nighthawks: Are gravel roofs important? Condor 91(3):722-724. https://doi.org/10.2307/1368127

Brigham, R. M., J. Ng, R. G. Poulin, and S. D. Grindal. 2011. Common Nighthawk (Chordeiles minor), version 2.0. In A. F. Poole, editor. The birds of North America. Cornell Lab of Ornithology, Ithaca, New York, USA. https://doi.org/10.2173/ bna.comnig.02

Caughley, G. 1994. Directions in conservation biology. Journal of Animal Ecology 63(2):215-244. https://doi.org/10.2307/5542

Chandler, R., and J. Hepinstall-Cymerman. 2016. Estimating the spatial scales of landscape effects on abundance. Landscape Ecology 31(6):1383-1394. https://doi.org/10.1007/s10980-016-0380$\mathrm{Z}$

Cink, C. L., P. Pyle, and M. A. Patten. 2017. Eastern Whip-poorwill (Antrostomus vociferus), version 3.0. In A. F. Poole, editor. The birds of North America. Cornell Lab of Ornithology, Ithaca, New York, USA. [online] URL: https://birdsna.org/SpeciesAccount/bna/species/whip-p1/introduction

Committee on the Status of Endangered Wildlife in Canada (COSEWIC). 2009. COSEWIC assessment and status report on the Whip-poor-will (Caprimulgus vociferus) in Canada. Ottawa, Ontario, Canada. [online] URL: https://www.canada.ca/en/ environment-climate-change/services/species-risk-public-registry/ cosewic-assessments-status-reports/whip-poor-will-2009.html 
Avian Conservation and Ecology 15(1): 24

Committee on the Status of Endangered Wildlife in Canada (COSEWIC). 2018. COSEWIC assessment and status report on the Common Nighthawk (Chordeiles minor) in Canada. Ottawa, Ontario, Canada. [online] URL: https://www.canada.ca/en/ environment-climate-change/services/species-risk-public-registry/ cosewic-assessments-status-reports/common-nighthawk-2018.html

Donald, P. F., R. E. Green, and M. F. Heath. 2001. Agricultural intensification and the collapse of Europe's farmland bird populations. Proceedings of the Royal Society B: Biological Sciences 268(1462):25-29. https://doi.org/10.1098/rspb.2000.1325

Ducks Unlimited Canada. 2010. Southern Ontario wetland conversion analysis: final report. [online] URL: https://www. ducks.ca/assets/2010/10/duc_ontariowca_optimized.pdf

Endenburg, S., G. W. Mitchell, P. Kirby, L. Fahrig, J. Pasher, and S. Wilson. 2019. The homogenizing influence of agriculture on forest bird communities at landscape scales. Landscape Ecology 34(10):2385-2399. https://doi.org/10.1007/s10980-019-00895-8

English, P. A., J. J. Nocera, B. A. Pond, and D. J. Green. 2017. Habitat and food supply across multiple spatial scales influence the distribution and abundance of a nocturnal aerial insectivore. Landscape Ecology 32(2):343-359. https://doi.org/10.1007/ s10980-016-0454-y

Environment and Climate Change Canada. 2019. Species at risk public registry. Ottawa, Ontario, Canada. [online] URL: https:// www.canada.ca/en/environment-climate-change/services/speciesrisk-public-registry.html

Esri Inc. 2016. ArcMap 10.5.1. Esri Inc., Redlands, California, USA.

Evans, K. L., J. D. Wilson, and R. B. Bradbury. 2007. Effects of crop type and aerial invertebrate abundance on foraging barn swallows Hirundo rustica. Agriculture, Ecosystems \& Environment 122(2):267-273. https://doi.org/10.1016/j.agee.2007.01.015

Farrell, C. E., L. Fahrig, G. Mitchell, and S. Wilson. 2019. Local habitat association does not inform landscape management of threatened birds. Landscape Ecology 34(6):1313-1327. https://doi. org/10.1007/s10980-019-00843-6

Farrell, C. E., S. Wilson, and G. Mitchell. 2017. Assessing the relative use of clearcuts, burned stands, and wetlands as breeding habitat for two declining aerial insectivores in the boreal forest. Forest Ecology and Management 386:62-70. https://doi. org/10.1016/j.foreco.2016.11.026

Fisette, T., P. Rollin, Z. Aly, L. Campbell, B. Daneshfar, P. Filyer, A. Smith, A. Davidson, J. Shang, and I. Jarvis. 2013. AAFC annual crop inventory: status and challenges. In AgroGeoinformatics 2013: the Second International Conference on Agro-Geoinformatics. August 12-16, 2013. Fairfax, Virginia, USA. https://doi.org/10.1109/Argo-Geoinformatics.2013.6621920

Fiske, I., and R. Chandler. 2020. Overview of unmarked: an R package for the analysis of data from unmarked animals. CRAN. [online] URL: http://cran.cc.uoc.gr/mirrors/CRAN/web/packages/ unmarked/vignettes/unmarked.pdf

Gehring, T. M., and R. K. Swihart. 2003. Body size, niche breadth, and ecologically scaled responses to habitat fragmentation: mammalian predators in an agricultural landscape. Biological
Conservation 109(2):283-295. https://doi.org/10.1016/S0006-3207 (02)00156-8

Guisan, A., R. Tingley, J. B. Baumgartner, I. Naujokaitis-Lewis, P. R. Sutcliffe, A. I. T. Tulloch, T. J. Regan, L. Brotons, E. McDonald-Madden, C. Mantyka-Pringle, T. G. Martin, J. R. Rhodes, R. Maggini, S. A. Setterfield, J. Elith, M. W. Schwartz, B. A. Wintle, O. Broennimann, M. Austin, S. Ferrier, M. R. Kearney, H. P. Possingham, and Y. M. Buckley. 2013. Predicting species distributions for conservation decisions. Ecology Letters 16(12):1424-1435. https://doi.org/10.1111/ele.12189

Hallmann, C. A., R. P. B. Foppen, C. A. M. van Turnhout, H. de Kroon, and E. Jongejans. 2014. Declines in insectivorous birds are associated with high neonicotinoid concentrations. Nature 511 (7509):341-343. https://doi.org/10.1038/nature13531

Harris, J. B., and D. G. Haskell. 2007. Land cover sampling biases associated with roadside bird surveys. Avian Conservation and Ecology 2(2):12. https://doi.org/10.5751/ACE-00201-020212

Jackson, H. B., and L. Fahrig. 2015. Are ecologists conducting research at the optimal scale? Global Ecology and Biogeography 24(1):52-63.

Knight, E. C., J. W. Ng, C. E. Mader, M. R. Brigham, and E. M. Bayne. 2018. "An inordinate fondness for beetles": first description of Common Nighthawk (Chordeiles minor) diet in the boreal biome. Wilson Journal of Ornithology 130(2):525-531. https://doi.org/10.1676/16-219.1

Lindenmayer, D. B., J. Fischer, and R. B. Cunningham. 2005. Native vegetation cover thresholds associated with species responses. Biological Conservation 124(3):311-316. https://doi. org/10.1016/j.biocon.2005.01.038

MacKenzie, D. I., J. D. Nichols, G. B. Lachman, S. Droege, J. A. Royle, and C. A. Langtimm. 2002. Estimating site occupancy rates when detection probabilities are less than one. Ecology 83 (8):2248-2255. https://doi.org/10.1890/0012-9658(2002)083[2248: ESORWD]2.0.CO;2

Michel, N. L., A. C. Smith, R. G. Clark, C. A. Morrissey, and K. A. Hobson. 2016. Differences in spatial synchrony and interspecific concordance inform guild-level population trends for aerial insectivorous birds. Ecography 39(8):774-786. https:// doi.org/10.1111/ecog.01798

Miguet, P., L. Fahrig, and C. Lavigne. 2017. How to quantify a distance-dependent landscape effect on a biological response. Methods in Ecology and Evolution 8(12):1717-1724. https://doi. org/10.1111/2041-210X.12830

Nebel, S., A. Mills, J. D. McCracken, and P. D. Taylor. 2010. Declines of aerial insectivores in North America follow a geographic gradient. Avian Conservation and Ecology 5(2):1. https://doi.org/10.5751/ACE-00391-050201

Paquette, S. R., D. Garant, F. Pelletier, and M. Bélisle. 2013. Seasonal patterns in Tree Swallow prey (Diptera) abundance are affected by agricultural intensification. Ecology Applications 23 (1):122-133. https://doi.org/10.1890/12-0068.1

Perlut, N. G., A. M. Strong, T. M. Donovan, and N. J. Buckley. 2006. Grassland songbirds in a dynamic management landscape: behavioral responses and management strategies. Ecological 
Applications 16(6):2235-2247. https://doi.org/10.1890/1051-0761 (2006)016[2235:GSIADM]2.0.CO;2

Put, J. E., L. Fahrig, and G. W. Mitchell. 2019. Bats respond negatively to increases in the amount and homogenization of agricultural land cover. Landscape Ecology 34(8):1889-1903. https://doi.org/10.1007/s10980-019-00855-2

R Core Team. 2017. R: a language and environment for statistical computing. R Foundation for Statistical Computing, Vienna, Austria.

Rempel, R. S., D. Kaukinen, and A. P. Carr. 2012. Patch analyst and patch grid. Ontario Ministry of Natural Resources, Centre for Northern Forest Ecosystem Research, Thunder Bay, Ontario, Canada.

Rushing, C. S., T. B. Ryder, and P. P. Marra. 2016. Quantifying drivers of population dynamics for a migratory bird throughout the annual cycle. Proceedings of the Royal Society B: Biological Sciences 283(1823):20152846. https://doi.org/10.1098/rspb.2015.2846

Schmidt, K. A. 2003. Nest predation and population declines in Illinois songbirds: a case for mesopredator effects. Conservation Biology 17(4):1141-1150. https://doi.org/10.1046/j.1523-1739.2003.02316. $\mathrm{x}$

Slover, C. L., and T. E. Katzner. 2016. Eastern Whip-poor-wills (Antrostomus vociferus) are positively associated with low elevation forest in the central Appalachians. Wilson Journal of Ornithology 128(4):846-856. https://doi.org/10.1676/15-156.1

Smith, A. C., M-A. R. Hudson, V. Aponte, and C. M. Francis. 2019. North American Breeding Bird Survey - Canadian trends website, data-version 2015. Environment and Climate Change Canada, Gatineau, Quebec, Canada. [online] URL: https:// wildlife-species.canada.ca/breeding-bird-survey-results

Spiller, K. J., and R. Dettmers. 2019. Evidence for multiple drivers of aerial insectivore declines in North America. Condor 121(2): duz010. https://doi.org/10.1093/condor/duz010

Spitzer, K., and H. V. Danks. 2006. Insect biodiversity of boreal peat bogs. Annual Review of Entomology 51(1):137-161. https:// doi.org/10.1146/annurev.ento.51.110104.151036

Stanton, R. L., C. A. Morrissey, and R. G. Clark. 2018. Analysis of trends and agricultural drivers of farmland bird declines in North America: a review. Agriculture, Ecosystems \& Environment 254:244-254. https://doi.org/10.1016/j.agee.2017.11.028

Statistics Canada. 2006. Census of agriculture. Ottawa, Ontario, Canada. [online] URL: https://www.statcan.gc.ca/ca-ra2006/ index-eng.htm

Statistics Canada. 2011. Census of agriculture. Glossary. Ottawa, Ontario, Canada. [online] URL: https://www.statcan.gc.ca/eng/ ca2011/gloss\#gt18
Stenger J. M., J. A. Rehm-Lorber, C. M. White, and D. C. Pavlacky Jr. 2011. Monitoring the birds of Agate Fossil Beds National Monument: 2010 annual report. Rocky Mountain Bird Observatory, Brighton, Colorado, USA.

Stoate C., A. Baldi, P. Beja, N. D. Boatman, I. Herzon, A. van Doorn, G. R. de Snoo, L. Rakosy, and C. Ramwell. 2009. Ecological impacts of early 21 st century agricultural change in Europe - a review. Journal of Environmental Management 91 (1):22-46. https://doi.org/10.1016/j.jenvman.2009.07.005

Suarez-Rubio, M., S. Wilson, P. Leimgruber, and T. Lookingbill. 2013. Threshold responses of forest birds to landscapes changes around exurban development. PloS ONE 8(6):e67593. https://doi. org/10.1371/journal.pone.0067593

Swift, T. L., and S. J. Hannon. 2010. Critical thresholds associated with habitat loss: a review of the concepts, evidence and applications. Biological Reviews 85(1):35-53. https://doi. org/10.1111/j.1469-185X.2009.00093.x

Tozer, D. C., J. C. Hoare, J. E. Inglis, J. Yaraskavitch, H. Kitching, and S. Dobbyn. 2014. Clearcut with seed trees in red pine forests associated with increased occupancy by Eastern Whip-poor-wills. Forest Ecology and Management 330:1-7. https://doi.org/10.1016/ j.foreco.2014.06.038

Twedt, D. J. 2015. Estimating regional landbird populations from enhanced North American Breeding Bird Surveys. Journal of Field Ornithology 86(4):352-368. https://doi.org/10.1111/jofo.12118

Wilson, M. D. 2003. Distribution, abundance, and home range of the Whip-poor-will (Caprimulgus vociferus) in a managed forest landscape. Thesis. College of William \& Mary, Williamsburg, Virginia, USA.

Wilson, M. D., and B. D. Watts. 2008. Landscape configuration effects on distribution and abundance of Whip-poor-wills. Wilson Journal of Ornithology 120(4):778-783. https://doi.org/10.1676/06-108.1

Wilson, S., S. L. Ladeau, A. P. Tøttrup, and P. P. Marra. 2011. Range-wide effects of breeding- and nonbreeding- season climate on the abundance of a Neotropical migrant songbird. Ecology 92 (9):1789-1798. https://doi.org/10.1890/10-1757.1

Wilson, S., G. W. Mitchell, J. Pasher, M. McGovern, M.-A. R. Hudson, and L. Fahrig. 2017. Influence of crop type, heterogeneity and woody structure on avian biodiversity in agricultural landscapes. Ecological Indicators 83:218-226. https:// doi.org/10.1016/j.ecolind.2017.07.059
Editor-in-Chief: Alexander L.Bond Subject Editor: Katie E.Sieving
Sponsored by the Society of Canadian Ornithologists and Birds Canada Parrainée par la Société des ornithologistes du Canada et Oiseaux Canada

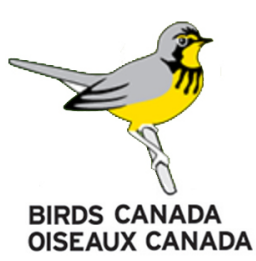




\section{Appendix 1}

Scale of effect analysis

In ecology, the scale of effect is the spatial extent of the landscape that has the strongest effect on a species response (Brennan et al. 2002, Jackson and Fahrig 2015). The scale of effect can be empirically calculated using a focal site multiscale study design where an ecological response (such as occupancy or abundance) is measured at each site and the landscape structure (such as proportion of habitat amount) is measured at multiple spatial extents around each focal site (Jackson and Fahrig 2015). In this study, we identified the scale of effect as the spatial extent with the lowest small-sample Akaike Information Criterion $\left(\mathrm{AIC}_{\mathrm{c}}\right)$ value for an ecological response. Other coefficients, criterion or indicators may be used to determine the scale of effect (Jackson and Fahrig 2015).

In our study we determined the appropriate landscape scale using a threshold-based method (TBM). However, some studies argue that the TBM is oversimplified because it assumes that the effect of the landscape variable on the response variable is the same at every point within the scale of effect (i.e. up to the threshold; Miguet et al. 2017). An alternative to the TBM is the distance-weighted method (DWM) that measures distance-weighted landscape variables from the measured response (Chandler and Hepinstall-Cymerman 2016, Miguet et al. 2017). In a study by Miguet and colleagues (2017), the authors compared TBM and DWM using real datasets and found that although the DWM may improve model support, model fit using AIC and $\mathrm{R}^{2}$ values between TBM and DWM were not significantly different (Miguet et al. 2017). The study by Miguet and colleagues (2017) also highlighted that the TBM may underestimate the area required for landscape management in comparison to the DWM. Although DWM may improve the TBM, the DWM is relatively new and not very commonly used. In our scale of effect 
analysis, we have used TBM because it is more commonly used and model fit is relatively similar to DWM. Since our scales may underestimate the area required for conservation, we do not emphasize the scale required for conservation other than the relative size (i.e. small vs large).

We empirically evaluated the scale of effect by selecting the spatial scale with the lowest AICc values for forest, agriculture, wetlands, urban, cropland and perennial forages at all 11 spatial scales $(500 \mathrm{~m}, 1000 \mathrm{~m}, 2000 \mathrm{~m}, 3000 \mathrm{~m}, 4000 \mathrm{~m}, 5000 \mathrm{~m}, 6000 \mathrm{~m}, 7000 \mathrm{~m}, 8000 \mathrm{~m}, 9000 \mathrm{~m}$ $10000 \mathrm{~m})$. The scale of effect for landscape composition measures for whip-poor-wills were $2000 \mathrm{~m}$ for proportion forest cover, $3000 \mathrm{~m}$ for proportion agricultural cover, $6000 \mathrm{~m}$ for proportion wetlands and 2000m for proportion urban (see figure S1). Within the agricultural category, the scale of effect for whip-poor-wills for cropland was $1000 \mathrm{~m}$ and $7000 \mathrm{~m}$ for perennial forages. Thus, for whip-poor-wills we used forest cover at 2000m, agriculture cover at $3000 \mathrm{~m}$, wetlands at $6000 \mathrm{~m}$, urban at $2000 \mathrm{~m}$, cropland at $1000 \mathrm{~m}$ and perennial forages at $7000 \mathrm{~m}$ in all models. 


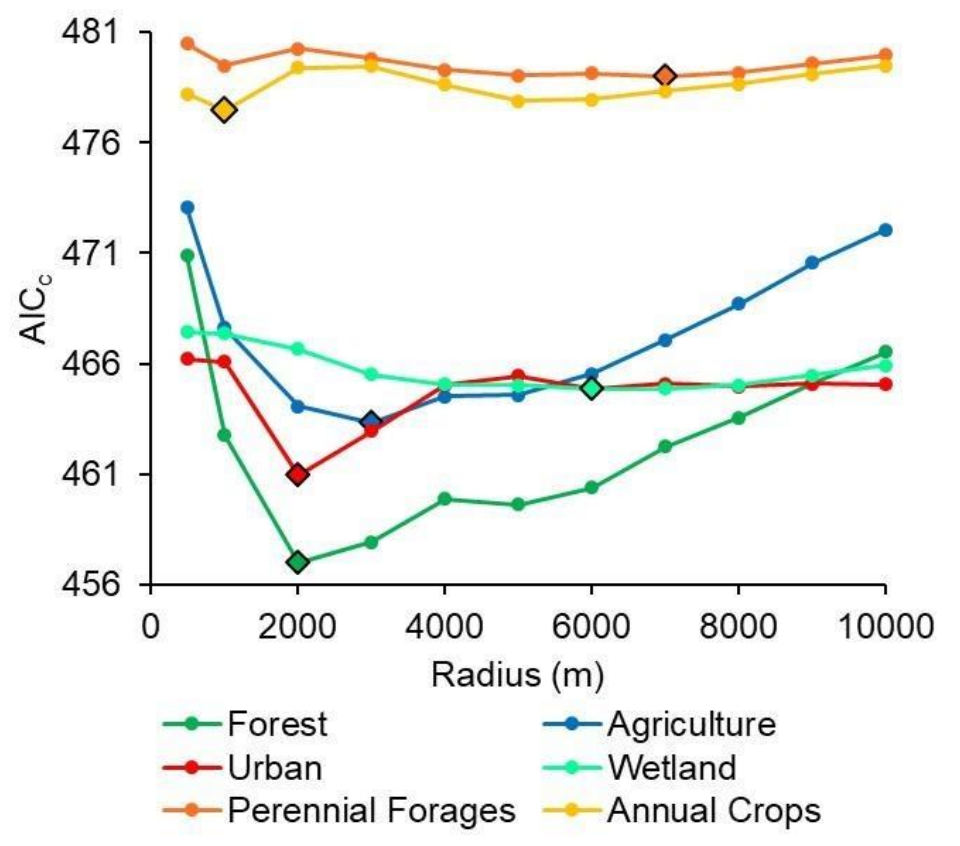

S1 - Scale of effect analysis of Eastern Whip-poor-will occupancy versus proportion of forest, agriculture, wetland, urban, cropland and perennial forages at various scales (radii in m). Scale of effect indicated by diamond (black outline). 